Pacific Journal of Mathematic 


\title{
QUOTIENTS OF THE SPACE OF IRRATIONALS
}

\author{
E. Michael And A. H. Stone
}

\begin{abstract}
It is proved that every metric space which is a continuous image of the irrationals is also a quotient of the irrationals.
\end{abstract}

In this paper we are concerned with the class $\mathscr{A}$ of all those metric spaces which are continuous images of complete separable metric spaces. The members of $\mathscr{A}$ are generally called "(absolutely) analytic sets" or " $A$-sets" [9] or "Souslin spaces" [5], and are known to be precisely those metric spaces which are either empty or are continuous images of the space $\boldsymbol{P}$ of irrational numbers ${ }^{1}$. Suppose, then, that $Y \in \mathscr{A}$ and $Y$ is nonempty. There exists a continuous surjection $f: P \rightarrow Y$; how "nice" can $f$ be taken to be? In general, $f$ cannot be one-toone (or $Y$ would have to be absolutely Borel; see [9 p. 487]); nor can $f$ be open or closed (as $Y$ would then be an absolute $G_{\dot{o}}$; see 3.4 and 3.5 below). However, we shall see that $f$ can always be chosen to be a quotient map. More precisely, we prove the following theorem.

THEOREM 1.1. Every metrizable space $Y$ which is a continuous image of $\boldsymbol{P}$ is also a quotient of $\boldsymbol{P}$ (under a different map, in general).

Since the space $\boldsymbol{Q}$ of rational numbers is in $\mathscr{A}$, Theorem 1.1 has the following rather striking consequence:

CoRollary 1.2. The space of rationals is a quotient of the space of irrationals.

The proof of Theorem 1.1 is given in the next section, after which we mention some generalizations, related results and open questions.

2. Proof of Theorem 1.1. The proof depends on the following characterization of $\boldsymbol{P}$, due to Hausdorff [7].

Lemma 2.1. A space $X$ is homeomorphic to $\boldsymbol{P}$ if and only if $X$ is a separable metrizable 0-dimensional absolute $G_{o}$ such that no nonempty open subset of $X$ is compact.

Now let $Y$ be a metrizable space which is a continuous image of $\boldsymbol{P}$, and let us show that $Y$ is a quotient of $\boldsymbol{P}$. Since $\boldsymbol{P}$ is separable,

1 While the reals are usually denoted by $\boldsymbol{R}$, and the rationals by $\boldsymbol{Q}$ (for quotient), there seems to be no standard symbol for the irrationals. The natural choice would be $\boldsymbol{I}$, but that has been pre-emptied by the unit interval. We therefore propose $\boldsymbol{P}$, which permits the equation $\boldsymbol{P} \cup \boldsymbol{Q}=\boldsymbol{R}$, and which may be thought of as standing for psychotic (=irrational). 
$Y$ has a countable base $\left\{V_{n}: n \in N\right\}$. We can choose this base, and the metric $d$ on $Y$, so that diam $V_{n} \rightarrow 0$, no $V_{n}$ is empty, and each $y \in Y$ is in $V_{n}$ for infinitely many $n$ (the $V_{n}$ need not all be distinct): For if $Y$ is compact we merely choose a sequence of finite open covers whose meshes decrease to 0 ; if $Y$ is not compact, we imbed it in a compact metric space $\bar{Y}$ and give $Y$ the metric and base it inherits from $\bar{Y}$.

We construct a subspace $X$ of the plane, and a map $f: X \rightarrow Y$, as follows. By assumption, there is a continuous surjection $g: P \rightarrow Y$. Let $X_{0}=\boldsymbol{P} \times\{0\}$. For each $n \in \boldsymbol{N}$ and each integer $j$, let

$$
A_{n j}=g^{-1}\left(V_{n}\right) \cap\left[\frac{j}{n}, \frac{j+1}{n}\right],
$$

and let

$$
X_{n j}=A_{n j} \times\left\{\frac{1}{n}\right\}
$$

For all $n \in N$, let $J_{n}=\left\{j: A_{n j} \neq \varnothing\right\}$. Finally, let

$$
X=X_{0} \cup \bigcup\left\{X_{n j}: n \in N, j \in J_{n}\right\} \text {. }
$$

Note that the sets $X_{0}, X_{n j}$ are all pairwise disjoint, and that each $X_{n j}$ is open-closed in $X$.

Let us now define $f: X \rightarrow Y$. First define $f_{0}: X_{0} \rightarrow Y$ by $f_{0}(s, 0)=$ $g(s)$. Next, if $n \in N$ and $j \in J_{n}$, then $X_{n j}$ is homeomorphic to the nonempty open subset $A_{n j}$ of $\boldsymbol{P}$, and hence (from Lemma 2.1) to $\boldsymbol{P}$. But $g^{-1}\left(V_{n}\right)$ is also homeomorphic to $\boldsymbol{P}$, for the same reason. Thus, by composing $g$ with a homeomorphism, we obtain a continuous surjection $f_{n j}: X_{n j} \rightarrow V_{n}$. We now define $f: X \rightarrow Y$ by taking

$$
f \mid X_{0}=f_{0} \text { and } f \mid X_{n j}=f_{n j}
$$

for all $n \in N$ and $j \in J_{n}$.

To complete the proof, we shall show that $X$ is homeomorphic to $\boldsymbol{P}$, and that $f$ is a quotient map. Again we use Lemma 2.1. Clearly $X$ is separable metric. It is 0 -dimensional by the sum theorem; and each nonempty open subset of $X$ has a closed subset homeomorphic to $\boldsymbol{P}$, and so cannot be compact. We have only to show that $X$ is $G_{\delta}$ in a complete metric space. Now $\boldsymbol{P}$ has a complete metric; hence so has $P \times\{0,1,1 / 2,1 / 3, \cdots\}$, and $X$ is obtained from the latter space by removing a closed set from each $P \times\{1 / n\}$. Thus $X$ is homeomorphic to $P$.

To show that $f$ is continuous, it suffices to check continuity at each $\left(s_{0}, 0\right) \in X_{0}$, since continuity at points of $X_{n j}$ is obvious. Suppose that $V$ is the $\varepsilon$-neighborhood of $f\left(s_{0}, 0\right)=g\left(s_{0}\right)$ in $Y$. Let $W$ be the $\varepsilon / 2$-neighborhood of $g\left(s_{0}\right)$ in $Y$, and pick $n_{0} \in N$ so that diam $V_{n}<\varepsilon / 2$ 
whenever $n \geqq n_{0}$. Let

$$
U=X \cap\left(g^{-1}(W) \times\left[0, \frac{1}{n_{0}}\right]\right),
$$

If $(s, 0) \in U$, then

$$
f(s, 0)=g(s) \in W \subset V .
$$

If $(s, 1 / n) \in U$, then $g(s) \in W, g(s) \in V_{n}$ and $n \geqq n_{0}$, so that

$$
\begin{aligned}
d\left(f\left(s, \frac{1}{n}\right), g\left(s_{0}\right)\right) & \leqq d\left(f\left(s, \frac{1}{n}\right), g(s)\right)+d\left(g(s), g\left(s_{0}\right)\right) \\
& <\frac{1}{2} \varepsilon+\frac{1}{2} \varepsilon=\varepsilon,
\end{aligned}
$$

and again $f(s, 1 / n) \in V$. Thus $f(U) \subset V$, and $f$ is continuous.

To show that $f$ is a quotient map, we prove the following slightly stronger result (which actually implies that $f$ is "bi-quotient" in the sense of [13]): If $y \in Y$, then there is an element $x \in f^{-1}(y)$ such that $f(U)$ is a neighborhood of $y$ in $Y$ whenever $U$ is a neighborhood of $x$ in $X$.

In fact, we have only to choose $x=(s, 0)$ in $f^{-1}(y) \cap X_{0}$ (that is, $\left.s \in g^{-1}(y)\right)$. There are arbitrarily large values of $n$ for which $y \in V_{n}$, and for each such $n$ there is a unique $j_{n} \in J_{n}$ such that $s \in A_{n j_{n}}$; moreover, if $n$ is large enough then $X_{n j_{n}} \subset U$ so that

$$
y \in V_{n}=f\left(X_{n j_{n}}\right) \subset f(U) \text {. }
$$

That completes the proof.

3. Some related results and problems.

3.1. By a similar, though more elaborate, argument one can prove Theorem 1.1 if the hypothesis that $Y$ is (necessarily separable) metric is replaced by the slightly weaker hypothesis that $Y$ has a countable base. (In effect, $Y$ need not be assumed regular.)

3.2. It would not suffice, in Theorem 1.1, to assume that $Y$ is first countable (instead of metrizable). There exists a continuous image of $\boldsymbol{P}$ which is first countable, regular $T_{1}$ and Lindelöf (hence paracompact), but which is not a quotient of any separable metric space; see [12, Example 12.1 and Corollary 11.5]. However, we don't know whether a regular $T_{1}$ space which is a continuous image of $\boldsymbol{P}$ and which is also a quotient of some separable metric space (such quotients are characterized in [12, Cor. 11.5]) is always a quotient of $\boldsymbol{P}$. 
3.3. Theorem 1.1 and its proof can be generalized to nonseparable metric spaces. If $B(m)$ denotes the "Baire space" of order $m$ (i.e., the product of $\boldsymbol{\aleph}_{0}$ discrete spaces each of cardinality $m$ ), then every metrizable space which is a continuous image of $B(m)$ is also a quotient of $B(m)$. When $m=\boldsymbol{\aleph}_{0}$, this is precisely Theorem 1.1. The generalization uses a characterization of $B(m)$ similar to Lemma 2.1 (see $[15$, p. 6]).

3.4. A nonempty separable metric space $Y$ is the image of $\boldsymbol{P}$ under an open continuous map if and only if $Y$ has a complete metric (or equivalently is an absolute $G_{\delta}$ ). "Only if" follows from a theorem of Hausdorff [6] asserting that every metrizable image of a complete metric space under a continuous open map has a complete metric. "If" was proved by Arhangel'skii [2, Corollary 4.7].

3.5. The assertion in 3.4 also holds if "open" is replaced by "closed". "Only if" now follows from a theorem of Vaīnšteīn [16] asserting that every metrizable image of a complete metric space under a closed continuous map has a complete metric. "If" is a recent result of R. Engelking [4]; he shows, more generally, that every nonempty complete metric space of weight $m$ is the image of $B(m)$ under closed a continuous map.

3.6. It can be shown, by methods similar to those in $\S 2$, that a space $Y$ will be the image of $\boldsymbol{P}$ under a continuous map which is both open and closed, if and only if $Y$ has a complete metric, is separable and zero-dimensional, and has the further property that each nonempty open compact subset has an isolated point (or, equivalently, no open subset of $Y$ is homeomorphic to the Cantor set).

3.7. A continuous map $f: X \rightarrow Y$ is called compact-covering if each compact subset of $Y$ is the image of some compact subset of $X$. For a continuous surjection $f$ of a complete metric space $X$ onto a metric space $Y$, it is known that if $f$ is open or closed it is compactcovering, and if $f$ is compact-covering it is a quotient map (see [12, Lemma 11.2], [3, § 2 Proposition 18], and [1, Theorem 15] or [11, Corollary 1.2]). We have seen that in Theorem 1.1 the quotient map cannot in general be chosen open or closed; can it always be chosen so that it is compact-covering? As we shall see, the answer is "no". In fact, we conjecture that $Y$ (assumed nonempty separable metric) is a compact-covering image of $\boldsymbol{P}$ if and only if $Y$ has a complete metric. "If" of course follows from 3.4 or 3.5 and can also be proved directly. In the other direction, it is not hard to show that $Y$ (assumed nonempty separable metric) is the image of $\boldsymbol{P}$ under a compact-covering 
map if and only if the space $\mathscr{K}(Y)$ of nonempty compact subsets of $Y$, equipped with the Hausdorff metric, is analytic. Now Hurewicz has shown that $\mathscr{K}(Q)$ is not analytic (in [8]; a simpler proof is in [10]). Thus, if $Y$ is a compact-covering image of $P$, it always has the following properties: It is analytic, and contains no closed (or $G_{\delta}$ ) subset homeomorphic to the space $\boldsymbol{Q}$ of rational numbers. These properties suggest that $Y$ ought to be an absolute $G_{\dot{o}}$, but unfortunately they do not suffice to prove it; Gödel and Novikov [14] have shown that it is (relatively) consistent with the usual axioms of set theory to suppose the contrary ${ }^{2}$. Thus our conjecture remains open.

\section{REFERENCES}

1. A. Arhangel'skii, Factor mappings of metric spaces, Dokl. Akad. Nauk SSSR 155 (1964), 247-250; Soviet Math. Dokl. 5 (1964), 368-371.

2. Open and close-to-open mappings. Relations among spaces, Trudy Moskov Mat. Obšč. 15 (1966), 181-223.

3. N. Bourbaki, Topologie Générale, Ch. 9 (2 $2^{\text {nd }}$ ed.), Paris, 1958.

4. R. Engelking, On closed images of the space of irrationals, Proc. Amer. Math. Soc.

(to appear)

5. F. Hausdorff, Mengenlehre, (3 ${ }^{\text {rd }}$ ed., reprinted, New York, 1964).

6. - Über innere Abbildungen, Fund. Math. 23 (1934), 279-291.

7. _ Die schlichten stetigen Bilder des Nullraumes, Fund. Math. 29 (1937), 151-158.

8. W. Hurewicz, Zur Theorie der analytischen Mengen, Fund. Math. 15 (1930), 4-17.

9. C. Kuratowski, Topology, Vol. 1, New York and London, 1966.

10. C. Kuratowski and E. Szpilrajn, Sur les cribles fermés et leurs applications, Fund. Math. 18 (1932), 160-170.

11. E. Michael, A note on closed maps and compact sets, Israel J. Math. 2 (1964), 173176.

12. E. Michael, $\aleph_{0}$-spaces, J. Math. and Mech. 15 (1966), 983-1002.

13. Bi-quotient maps and cartesian products of quotient maps, Ann. Inst. Fourier (Grenoble) (to appear)

14. P. S. Novikov, On the uncontradictability of certain properties of the descriptive theory of sets, Trudy Mat. Inst. Steklov 38 (1951), 279-316.

15. A. H. Stone, Non-separable Borel sets, Rozprawy Matematyczne 28 (1962).

16. I. A. Vaǐnšteǐn, On closed mappings of metric spaces, Doklady Akad. Nauk SSSR (NS) 57 (1947), 319-321.

Received August 22, 1968. Both authors gratefully acknowledge support by the National Science Foundation.

UNIVERSITY OF WASHINGTON AND

UNIVERSITY OF ROCHESTER

${ }^{2}$ We are indebted to Professor C. Kuratowski for calling our attention to this result. 



\section{PACIFIC JOURNAL OF MATHEMATICS}

\section{EDITORS}

\author{
H. ROYDEN \\ Stanford University \\ Stanford, California \\ R. R Phelps \\ University of Washington \\ Seattle, Washington 98105
}

\author{
J. Dugundui \\ Department of Mathematics \\ University of Southern California \\ Los Angeles, California 90007
}

RICHARD ARENS

University of California

Los Angeles, California 90024

\section{ASSOCIATE EDITORS}
E. F. BeCKENBACH
B. H. NeUmanN
F. WolF
K. YosidA

\section{SUPPORTING INSTITUTIONS}

\author{
UNIVERSITY OF BRITISH COLUMBIA \\ CALIFORNIA INSTITUTE OF TECHNOLOGY \\ UNIVERSITY OF CALIFORNIA \\ MONTANA STATE UNIVERSITY \\ UNIVERSITY OF NEVADA \\ NEW MEXICO STATE UNIVERSITY \\ OREGON STATE UNIVERSITY \\ UNIVERSITY OF OREGON \\ OSAKA UNIVERSITY \\ UNIVERSITY OF SOUTHERN CALIFORNIA
}

\author{
STANFORD UNIVERSITY \\ UNIVERSITY OF TOKYO \\ UNIVERSITY OF UTAH \\ WASHINGTON STATE UNIVERSITY \\ UNIVERSITY OF WASHINGTON

$* * * * *$
AMERICAN MATHEMATICAL SOCIETY
CHEVRON RESEARCH CORPORATION
TRW SYSTEMS
NAVAL WEAPONS CENTER

The Supporting Institutions listed above contribute to the cost of publication of this Journal, but they are not owners or publishers and have no responsibility for its content or policies.

Mathematical papers intended for publication in the Pacific Journal of Mathematics should be in typed form or offset-reproduced, double spaced with large margins. Underline Greek letters in red, German in green, and script in blue. The first paragraph or two must be capable of being used separately as a synopsis of the entire paper. It should not contain references to the bibliography. Manuscripts, in duplicate if possible, may be sent to any one of the four editors. Please classify according to the scheme of Math. Rev. 36, 1539-1546. All other communications to the editors should be addressed to the managing editor, Richard Arens, University of California, Los Angeles, California, 90024.

50 reprints are provided free for each article; additional copies may be obtained at cost in multiples of 50 .

The Pacific Journal of Mathematics is published monthly. Effective with Volume 16 the price per volume (3 numbers) is $\$ 8.00$; single issues, $\$ 3.00$. Special price for current issues to individual faculty members of supporting institutions and to individual members of the American Mathematical Society: $\$ 4.00$ per volume; single issues $\$ 1.50$. Back numbers are available.

Subscriptions, orders for back numbers, and changes of address should be sent to Pacific Journal of Mathematics, 103 Highland Boulevard, Berkeley, California, 94708.

PUBLISHED BY PACIFIC JOURNAL OF MATHEMATICS, A NON-PROFIT CORPORATION

Printed at Kokusai Bunken Insatsusha (International Academic Printing Co., Ltd.), 7-17. Fujimi 2-chome, Chiyoda-ku, Tokyo, Japan. 


\section{Pacific Journal of Mathematics}

Vol. 28, No. 3

May, 1969

Jon F. Carlson, Automorphisms of groups of similitudes over $F_{3} \ldots \ldots \ldots$

W. Wistar (William) Comfort, Neil Hindman and Stelios A. Negrepontis,

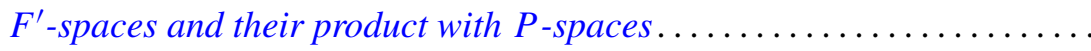

Archie Gail Gibson, Triples of operator-valued functions related to the unit

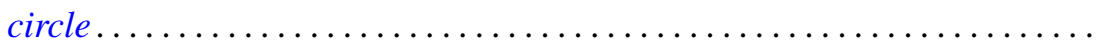

David Saul Gillman, Free curves in $E^{3}$

E. A. Heard and James Howard Wells, An interpolation problem for

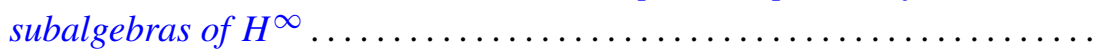

Albert Emerson Hurd, A uniqueness theorem for weak solutions of symmetric

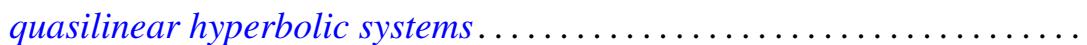

E. W. Johnson and J. P. Lediaev, Representable distributive Noether

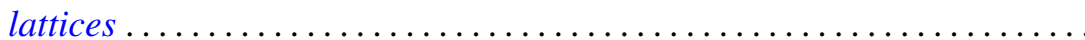

David G. Kendall, Incidence matrices, interval graphs and seriation in

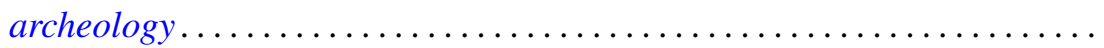
565

Robert Leroy Kruse, On the join of subnormal elements in a lattice ....... 571

D. B. Lahiri, Some restricted partition functions; Congruences modulo 3 .... 575

Norman D. Lane and Kamla Devi Singh, Strong cyclic, parabolic and conical differentiability........................................

William Franklin Lucas, Games with unique solutions that are

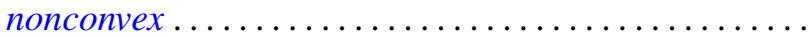

Eugene A. Maier, Representation of real numbers by generalized geometric series.

Daniel Paul Maki, A note on recursively defined orthogonal polynomials ...

Mark Mandelker, $F^{\prime}$-spaces and z-embedded subspaces ...

James R. McLaughlin and Justin Jesse Price, Comparison of Haar series with gaps with trigonometric series

Ernest A. Michael and A. H. Stone, Quotients of the space of irrationals ....

William H. Mills and Neal Zierler, On a conjecture of Golomb ...

J. N. Pandey, An extension of Haimo's form of Hankel convolutions ...

Terence John Reed, On the boundary correspondence of quasiconformal mappings of domains bounded by quasicircles...

Haskell Paul Rosenthal, A characterization of the linear sets satisfying Herz's criterion.

George Thomas Sallee, The maximal set of constant width in a lattice...

I. H. Sheth, On normaloid operators

James D. Stasheff, Torsion in BBSO ...

Billy Joe Thorne, A - P congruences on Baer semigroups.

Robert Breckenridge Warfield, Jr., Purity and algebraic compactness for

modules... 